\title{
Empirical Research on the Latent Factors that Facilitate the Individuals' Interaction with the Community
}

\author{
Ion Tudor ${ }^{1}$, Cristina State ${ }^{1}$ and Valentina Nicolae ${ }^{1}$
}

\begin{abstract}
The communion of interests and the open, voluntary membership which characterise social economy enterprises are a challenge we will be trying to deal with in this paper. Our dilemma regarding the existence of some conditionality between the individuals' expectations from their community and their availability to get involved in solving community problems has become the main objective of the study. Solving this dilemma came as a natural consequence of the initiation of a questionnaire-based study, including separate sets of questions concerning the perception of the participants about how the community meets their expectations, combined with questions about their availability to act to the benefit of the community. The work hypotheses were tested with the IBM Statistics and Microsoft Excel applications. The results obtained after testing the hypotheses signal two important aspects: on the one hand, the availability of the participants in the study to act for the benefit of their communities is not conditional on the expectations they have from the community and, on the other hand, at the time of the survey, the preference of the study participants to act for the benefit of the community is not sufficiently well defined.
\end{abstract}

Keywords: communities, social economic enterprise, solidarity, social implication

\section{Introduction}

This paper completes our scientific research on "Improving the management of the social economy enterprise, a key factor for the sustainable development of local communities", giving it a new valence this time by deepening the study on the latent factors of the individuals' interaction with the community.

Two distinct ideas emerged from our previously published work: 1), the views of young people (participants in the pilot study) concerning their involvement in voluntary activities was not defined at the time of the survey (Popescu, D., Sanchez, G., and all, 2015, pp. 65) and, 2) although the social economy and social economy enterprises are less known (by the participants in the current study, which we initiated in the summer of 2015), we identified people who assume social responsibility by engaging in volunteer activities (individually or in an organized framework, in social economy structures!) thus participating in the creation of tangible and intangible values for their fellows or for the community. The motivations of the subjects to engage in volunteering are related to manifesting their sense of solidarity, the need for social involvement, the need to be helpful and not least, the desire for self-affirmation.

The current study assumes that in any developed society there should be a viable, welldefined social economic sector, actively involved in community life. Social economy enterprises have the responsibility and the role of generating wealth for their members and for the community and of binding together the social actors. 
By their nature, social economy enterprises have a number of distinctive features which differentiate them from economic agents in the public or private sector, including: giving priority to achieving social objectives, applying the principle of solidarity and responsibility, the communion of interests of the members with the general interest, the democratic control exerted by the members, management autonomy and independence from public authorities, voluntary adhesion, participatory management and, not least, the profit / surplus distribution for achieving the social goals.

In the contemporary society, social economy enterprises must answer several questions and challenges, including: Can social activities be achieved in the absence of profit-generating economic activities?, What kind of benefits do social economy enterprises bring?, Are the benefits of social economy enterprises obtained as individual gain, or for the organization / community?, What kind of values do social economy enterprises produce?, What is the added value brought by social economy enterprises to the community?

Social economy enterprises operate as economic producers of goods and services, according to the law of demand and supply and redirect their profit to meet the (social, educational or environmental) goals they have assumed for their members and / or the community. The performance of social economy enterprises is measured using economic indicators that are easy to assess and to express and social impact indicators, relatively difficult to assess in the absence of unanimously accepted sectoral or social standards that reflect their contribution to developing solidarity, responsibility and social cohesion. The entrepreneurs, the management team, the products or services offered, all play an important role in improving the performance of social economy enterprises.

Social cohesion is recognized and identified in behaviours, attitudes and effects of the work done by community members (Apud, Ailenei, D., \& All, pp. 17). Social cohesion is built on the social capital created in the social relations that are established by engaging in various (paid or voluntary) activities organized by the social economy enterprises and is maintained and experienced by the individuals involved in such activities. The essence of the social capital that is formed within the community, based on social relations, can be seen as a resource for the users of the services provided by social economy enterprises. In their turn, social economy enterprises have the ability to create lucrative social networks, in the local communities, based on the complementarity of economic exchanges. In their turn, these networks are the basis of the social capital at community level.

In our brief introduction, we have mentioned only a few elements which we consider to be relevant in order to justify the need for continuing the research on identifying the latent factors that facilitate the interaction between individuals and the community.

\section{Literature Review}

A number of researchers, among which we mention Pierre Bourdieu, James Coleman and Robert Samuel Putnam, define social capital as a set of social networks, characterized by trust and reciprocity norms that develop in a specific institutional context (Apud Sibony, D., 2013, pp. 182).

The number and quality of these relationships influence the individuals' ability to collectively approach the common problems they are being faced with, so that everyone 
wins (win - to - win) (Sibony, D., 2013, pp. 182).

The paradigm of sustainable development as a unanimously accepted model facilitates the creation of the network effect, including at the social economy enterprise level. The availability of social economy enterprises to collectively bring a high social value in the community, through their unique offer of products and services, leading to the creation of genuine social networking. An intangible capital is thus formed, which does not appear in the balance sheet but which contributes to creating value in the community (Persais, E., 2013, pp. 3).

It seems that the notion of social capital was enunciated for the first time by the American economist Robert Putnam, in 1993 (https://en.wikipedia.org/wiki/Robert D. Putnam, accessed on 31.03.2016, at 4.20 p.m). By analogy with the notions of physical capital and human capital, social capital is characteristic of social organization, such as networks, norms and trust, which facilitate the coordination and cooperation for the mutual benefit. Consequently, the social capital enhances the benefits of the investment in physical and human capital. According to Putnam, current communities have not become civic simply because they were rich, but on the contrary, history suggests the exact opposite: they became rich because they were civic. Thus, the social capital represented by norms and networks of civic engagement seems to be a prerequisite for economic development and for effective governance (Putnam, R.D., 1993, pp.35-36).

A reticular analysis of the economy - which focuses among other things on the presence and density of interpersonal relationship - combined with the cultural analysis of the economy - which establishes connections among market values - makes it possible to understand and to tackle social economy as a "social capital economy", understood as an organisational factor and a generator of meaning, as shown in the thesis „Social capital, philanthropy and identity: what implications for the social economy?" (Sibony, D., 2013, pp. 8).

According to Demoustier, the social economy enterprise can be seen as a combination between an association and an enterprise from an institutional point of view. In this "equation", the enterprise has an all-encompassing character, which will enable the social economy enterprise to affirm itself as a social construction which produces values, standards and norms, as a socio-economic actor (Demoustier, D., Colletis, G.,2012. pp. 21).

Social and Solidarity Economy has become a growing social movement, with a range of activities that share common values, focusing on the development at community level.

Thus, in the study ,"The social and solidarity economy towards greater 'sustainability': learning across contexts and cultures, from Geneva to Manila" the authors conclude that social economy has the potential to become a sustainable economy, working towards sustainable community development (Sahakian, M.D., Dunand, C, 2014, pp. 403). In this sense, according to the authors, more consistency is needed, not only within organizations but also among activities, communities and world regions.

Another study that caught our attention, entitled "The challenges of combining social and commercial enterprise", mentions that, over time, the organizations in the social sector have provided goods and services which had they been available in private markets, they may not have been appropriate or properly rendered. In the same study, the authors state that social economy enterprises endeavour to increase the welfare of the community, their management being adapted more to their mission than to the market rules (Dees, J.G., \& 
Elias, J., 1994, pp. 2). Therefore, one can understand the efforts made by the social economy enterprises to improve the quality of life of the people in the communities where they operate. Because this is the specific trait of the social, which is built by the people and it is natural that it should be for people, according to the affirmation of Ion Mărginean in the article „The Romanian social model in terms of quality of life” (Mărginean, I., 2004, pp. 213).

Referring to the impact of the crisis on the activity of European companies, in their paper „The social enterprise as an alternative economic model for small and medium-sized enterprises. Examples of successful social enterprises", Zheliazkov and Stoyanov show that not even social enterprises are immune to the impact of this crisis, and the politicians should not believe that social enterprises can fill all the gaps caused by austerity in the provision of services, or create sufficient work places to overcome the job crisis. According to the authors, social enterprises are not a panacea to social and economic challenges that arise in modern societies, but social economy is an important, viable instrument to meet these challenges (Zheliazkov, G., Stoyanov, K., 2015, pp. 277). Moreover, according to Claudia Petrescu's statements following the completion of an extensive study, social economy entities may prove effective especially in small communities, where the success is closely related to the changes in attitudes and behaviour, and the links among the members are strong (Petrescu, C., 2013, pp. 21). The same author notes that „local development in Romania meant introducing elements of social innovation such as: participatory approach to the social and economic growth process, partnership governance, the creation of new institutional structures in partnership, the partnership between communities, strategic planning” (Petrescu, C., 2013, pp. 22).

Remaining in the Romanian geographical area, in order to understand social economy as a local phenomenon, we find out from the work ,The Social Economy in Romania, between praxis and the need of conceptualizing practice", that social economy was originally developed as a major area of intervention through structural projects and subsequently as a conceptual model. The authors explain that in this way the first to be targeted were the vulnerable groups who were initially trained in a particular field and then placed in a work place. Later, projects were developed for creating social enterprises in rural areas, a move which proved to be insufficient, followed by the setting up of social enterprises operating according to the rules of economic profitability, which (in the absence of an appropriate regulatory framework) have not proven to be a durable solution. One conclusion of the authors is that the fact that rural communities should benefit from a better future by strengthening associativity, developing responsibility, involvement, trust and participation. However, the implementation of social economy enterprises proves to be difficult, mainly due to our relatively recent past, when these attitudes were devalued and misinterpreted (Cozarescu, M., 2012, pp. 133).

The concern to overcome the system crisis and to recover from the failures of the economic and social systems is high on the agenda of governments. The work "The New Regulatory Regime for Social Enterprises in Canada: Potential Impacts on Non-profit Growth and Sustainability" underlines the urgency to adapt and reshape the ways in which the economy and communities works (O’Connor, P., 2014, pp.7).

An answer to the search for alternatives, as revealed in the paper "Reciprocal Relationships: The Role of Government and the Social Economy in the Co-construction of Social Policy in Atlantic Canada" is to support and develop the social economy, by means of social and 
community enterprises. The solution proposed, following consultations, envisages the instatement of reciprocity and fairness between different bodies and the representatives of the social economy sector, in order to build policies, legislation and structures to harness the potential of social economy enterprises. The authors consider that when promoting such mutual relations it is important to take into account how the social economy enterprises may appear, so that the partnership would be fair (Myers, J., Mcdonald, M., 2014, pp 23).

A work that drew our attention because of its eminently practical structure is entitled: „Social capital: a guide to its measurement. Health \& place”, where the authors are aiming to revise the concept of social capital and its related constructs and to provide a brief guide for their operationalisation and measurement. The four existing constructs mentioned by the authors and analysed: collective effectiveness, the psychological sense of community, cohesion - neighbourhood and community competence. Although slightly different, each of these constructs partially covers social capital aspects (Lochner, K., Kawachi, I. și Kennedy, B.P., 1999 pp. 259).

The analysis highlights two distinct ideas: 1) Currently, there is no single definition of social capital, just as there is no single definition of other concepts at community level. The various tools used highlight common aspects, such as: the characteristics of social relationships at community level, the civic participation in voluntary associations, the mutual aid norms, the level of interpersonal trust, while the availability of several measurement instruments requires a study where they are all administered simultaneously, in order to examine the degree of shared variance. 2) A strong and consistent theme emerging from this review is the almost universal agreement that the characteristics of the community should be differentiated depending on the individual characteristics and measured at community level (Lochner, K., Kawachi, I. și Kennedy, B.P., 1999 pp.267).

At the end of this brief literature review, we can agree with Michael Woolcock who, in 1998, in his work „Social capital and economic development: Toward a theoretical synthesis and policy framework. Theory and society" said that the fact that "the challenge for theoreticians and policy makers alike is to identify the mechanisms that will create, nurture and support the types and combinations of social relations favourable to building participatory dynamic societies, sustainable, equitable economies, and states of responsible development" (Woolcock, M., 1998, pp. 180), This assertion lends itself exceptionally to the specific of social economy enterprises.

\section{Objectives, Hypotheses and Work Methodology}

The social economy enterprise is an economic actor, operating in a free market, in an ever more aggressive and competitive environment, with the aim of making profit to achieve its social objectives characterized, among other things, by: solidarity, responsibility, communion of interests of the members with the community interest and voluntary adhesion of the members. The distinctive features of this type of enterprise were the initial impulse that motivated us to deepen the study on the latent factors of the individuals' interaction with the community. The study results will allow us to understand the mechanism that makes the individuals' voluntary adhesion to the social economy enterprises possible and how these companies fulfil their social role in the community. 
Thus, the main objective of the paper is to identify the existence of any conditionality between the expectations that the participants in the study have from their community and their availability to work for the community benefit. At a careful look, the postulate according to which man is, by excellence, a social being, integrated into a community by means of which he establishes relations and makes progress, contains the answer to our question. The level of acceptance of the individual by the community and the quality of the collaboration among the individuals forming the community contribute to the development of emotional intelligence, the training of leaders and strengthens the individuals' attachment to the community - to name just a few arguments in favour of our approach. On the other hand, according to Phil Bartle, ,the community is a "sociological construct." It is a set of interactions, human behaviours that have meaning and expectations between its members. Not just an action, but actions based on shared expectations, values, beliefs and meanings between individuals" (http://cec.vcn.bc.ca/cmp/modules/index.htm, accessed on 02.03.2016, at 9.30 a.m.).

To define the human need for relationships with the community, we propose the following: 1) defining a construct of individual expectations and, 2) checking if there is a significant link between the defined construct and the individuals' decision to act for the community benefit.

The individual expectations construct was shaped as a result of the response received from the participants in the survey to the question: "On a scale from 1 to 5, where 1 is "very small" and 5 is "very big", it is most likely that the community will answer to your need (to be): accepted, admired, appreciated, approved, confirmed, credible, secure, encouraged, cared for, understood, recognized and respected"?

We defined the individual expectations construct using 12 items that represent the basic human needs related to the interaction with community members, as follows: (the ordering is made according to the Romanian alphabet, in order to highlight the fact that each item is treated equally): the need to be accepted, admired, appreciated, approved, confirmed, credible, secure, encouraged, cared for, understood, recognized and respected. The items (questions) are answered on a scale from 1 to 5 , where 1 is very small and 5 is very big. The total score of the questionnaire can vary between a minimum of 12 points and a maximum of 60 points.

In subsidiary, we established a secondary objective in order to check whether the decision of the participants in the study to act for the benefit of the community is influenced by the "biological gender" variable.

To achieve the main objective of the study we formulated the following assumptions, which we subsequently tested in the IBM SPSS application:

The null hypothesis (HO): there is no relationship between the individual expectations that the participants in the study have from their communities and their decision to support the community.

The alternative hypothesis (H1): there is a significant relationship between the individual expectations that the participants in the study have from their communities and their decision to support the community.

To achieve the secondary objective of the study, we will analyse the frequency of the responses received from the participants in the study (combined with the analysis of the correlation or association coefficients, as the situation requires) to the question: „Assuming you were asked today to support the community where you live, how would you act? With the 
following answers: 1. I would engage without hesitation; 2. I would ask first why my involvement is necessary; 3. I would let other people get involved first, and I would act afterwards; 4. I would first check the veracity of the information; 5 . The community can manage very well without me", for which we formulated the following work assumptions (also tested in the IBM SPSS application):

The null hypothesis (HO): the response options are equally preferred by the surveyed subjects.

The alternative hypothesis (H1): a particular variant of answer is preferred by the surveyed subjects.

The research was conducted as a (direct and online) survey, for which we used the selfadministered questionnaire (as primary data collection tool).

Synthetically, the methodology is presented in Table 1:

Table 1: Research Methodology

\begin{tabular}{|l|l|}
\hline Type of research: & Quantitative \\
The research method: & Survey \\
Primary data collection instrument: & Questionnaire, self-administered, directly and online \\
Measurement instrument: & 5-point Likert scale \\
Sampling: & By convenience, snowball method \\
Sample size: & 173 people \\
Target group: & People aged between18-70 years \\
Deployment territory: & Romania and Romanians from diaspora \\
Analysis method: & Factorial statistical analysis and data analysis \\
\hline *Ongoing study, the questionnaire is available online at: bttp://goo.gl/forms/eUWK17XLLQ \\
\hline
\end{tabular}

Source: Summary, realized by the authors

Up to the date when this paper was written, the responses to 173 questionnaires had been validated. Primary data collection is carried out within a wider research study that aims to highlight the degree of awareness regarding social economy.

The questionnaire, which was self-managed, directly and online, contains a set of questions concerning the perception of the participants in the study on how the community meets their expectations; the answers are sized on a 5-point Likert scale, where 1 means very small and 5 is very big (Likert, 1932, pp. 44).

For sampling we used the non probabilistic method, by convenience - the snowball method, beginning with addresses in our personal e-mail account, containing people belonging to the target group. The method requires the subjects to recommend, in their turn, other people who are part of the interest group by sending them the link to the site where the questionnaire is published.

The target group selection was made according to the following criteria:

- Participants in the study are people in Romania or Romanians in the diaspora;

- The age of the participants in the study is between 18 and 70 years;

- The participants in the study have online activity, a criterion which is fulfilled by the fact that they have an email account, through which they could be contacted.

Contacting of the surveyed subjects was carried out following the approach proposed by Dillman (Apud Hoddinott, S.N., 1986, pp. 2366) who considers that the use of a personalized method of contacting, repeated after an interval of time, increases the availability of the subjects regarding their participation in survey and leads to a higher 
response rate.

Primary data collection was conducted through self-administration of the questionnaire. In this way, we gave the surveyed subjects the opportunity to express themselves more fully, both in terms of the content and the form of the response. So, we benefited from a number of advantages of the questionnaire's self-administration, such as: a high degree of certainty regarding the drafting of the response, the influence of the operator's personality is eliminated, a large number of people can respond simultaneously, the interview effect is diminished, there is a higher concentration of the respondents on the answers, the anonymity is preserved, etc (Chelcea, S., 2001, pp. 84). We simultaneously aimed at eliminating the disadvantages posed by the self-administration of the questionnaire, such as: the risk of misunderstanding of the questions, the inability to obtain additional information, the ability to administer the questionnaire only from a certain level of culture and age upwards. To eliminate these disadvantages as much as possible we made our email addresses available to the interested surveyed subjects, so that we could be easily contacted.

Primary data collection was performed as follows:

1. The distribution of the hard copies of the questionnaire was done by directly approaching the people who meet the target group criteria;

2. The people contacted by email were addressed by their names or in a general manner (this is, in particular, the case of the people in the occupational groups with which we interact constantly) and they were invited to participate in this study;

3. Each email sent contains the link to the website that can be accessed to complete the questionnaire (http://goo.gl/forms/eUWK17XLLQ);

4. Three weeks after the first contact, a reminder was sent by email in connection with the survey participation.

Following the distribution of the questionnaire, a number of 204 complete questionnaires was registered, of which we validated 173 questionnaires for our research. The sampling method that we used does not allow us to estimate the number of people who saw and received the invitation to participate in the survey, so we cannot calculate the return rate of the responses. We chose not to use the option of filtering the responses, as the likelihood that the same IP would be accessed by multiple subjects is relatively high (e.g. using the same computer on a university campus, in a public space, in an office or even in the same household).

The questionnaire we have used contains four different chapters of interest for our research topic regarding "Improving the management of social economy enterprises, an essential factor of the responsible development of local communities", of which, for the purpose of the present paper, we have retained only the data regarding the relationship between individuals and the community and how these relationships influence the individuals' decision to support the community.

To achieve the proposed objectives, we will go through the following steps:

1. basic statistical inventory analysis;

2. analysis of the dimensionality, validity and reliability of the construct scale. Checking the scale fidelity is carried out by going through the following algorithm (in IBM SPSS application):

a) We calculate the internal consistency coefficient, Cronbach $\propto$, 


\section{b) Calculation of descriptive statistics:}

- for each item included in the analysis. The statistics we are concerned with at item level refer to the mean, standard deviation, interquartile (IQR) and the number of cases for each item analysed;

- at scale level. At this level we are interested in: mean, variance and standard deviation of the scale (all items subject to analysis) and the total number of items;

- for the scale, when an item is removed. We chose to display the composition of the scale at item elimination, because we want to know how the scale behaves if that item no longer exists. In this version we will include: the scale mean and variance, if that item is removed, the scale-item correlation, the behaviour of the new fidelity coefficient, if the item is no longer included in the scale.

c) Calculation of the correlations and covariance matrix of the scale items, which allows us a detailed study of the scale composition;

d) Calculation of the cumulative statistics;

e) Testing the hypothesis of equal mean using the „Hotelling's T-square” test, starting from the null hypothesis, of the equal mean of the items that compose the scale;

3. Testing the work assumptions

\section{Results}

The variables under investigation are presented in Table 2.

Table 2. Variable Information

\begin{tabular}{|c|c|c|c|c|}
\hline Variable & Position & Label & Measurement Level & Role \\
\hline GenB & 5 & GenB & Nominal & Input - Independent \\
accepted & 11 & accepted & Ordinal & Input - Independent \\
understood & 12 & understood & Ordinal & Input - Independent \\
admired & 13 & admired & Ordinal & Input - Independent \\
confirmed & 14 & confirmed & Ordinal & Input - Independent \\
recognized & 15 & recognized & Ordinal & Input - Independent \\
secure & 16 & secure & Ordinal & Input - Independent \\
approved & 17 & approved & Ordinal & Input - Independent \\
encouraged & 18 & encouraged & Ordinal & Input - Independent \\
respected & 19 & respected & Ordinal & Input - Independent \\
credible & 20 & credible & Ordinal & Input - Independent \\
appreciated & 21 & appreciated & Ordinal & Input - Independent \\
cared for & 22 & cared for & Ordinal & Input - Independent \\
ActionC & 38 & ActionC & Nominal & Input - Dependent \\
\hline
\end{tabular}

Source: data processing by the authors, SPSS

\subsection{Basic Statistical Inventory for the gender variable (Tables 3 and 4)}

The study involved a total of 173 subjects $(75$ men, "minimum" score $=1$ and 98 women "maximum" score $=2$ ) without any missing subject. The variable distribution can be treated as normal, uni-modal (mode $=2$ ), symmetrical (Skewness $=-0.271$; Skewness standard error $=0.185 ;$ zSkewness $=-1.464)$ and mesokurtic $($ Kurtosis $=-1.949$; standard 
error Kurtosis $=0.367$; zurtosis $=-5.310)$.

The analysis of the normality distribution, for the gender variable, was carried out using the method of the standard score, $\boldsymbol{z}$, which involved the following steps:

a) dividing the indicator $\left(\boldsymbol{S}_{\boldsymbol{k}}, \boldsymbol{K}\right)$ to its standard error $\left(\boldsymbol{E}_{\boldsymbol{k}}, \boldsymbol{E}_{\boldsymbol{K}}\right)$;

$$
\begin{array}{ll}
\boldsymbol{z}_{\boldsymbol{S} \boldsymbol{k}}=\boldsymbol{S}_{\boldsymbol{k}} / \boldsymbol{E}_{\boldsymbol{s}_{\boldsymbol{k}}} & \text { for symmetry } \\
\boldsymbol{z}_{\boldsymbol{K}}=\boldsymbol{K} / \boldsymbol{E}_{\boldsymbol{K}} & \text { for Kurtosis }
\end{array}
$$

b) comparing the standardized score value, obtained by calculation, with the threshold value of $\boldsymbol{z}$ distribution, provided we admit that the threshold value $\boldsymbol{p}<\mathbf{0 . 0 5}$, which corresponds to the $\boldsymbol{z}$-score normalized value of 1.96. If the calculated $\boldsymbol{z}$-score value is lower than the standardized threshold, the distribution may be treated as a symmetric distribution (Opariuc-Dan, 2009, pp. 194).

$z_{S k}=-0.271 / 0.185=-1.464<1.96$

$z_{K}=-1.949 / 0.367=-5.310<1.96$

Table 3. Statistics - the Gen variable

\begin{tabular}{|l|c|c|}
\hline \multicolumn{1}{|c|}{$\mathrm{N}$} & \multicolumn{1}{c|}{ Valid } & 173 \\
Missing & 0 \\
Median & & 2.00 \\
Mode & & 2 \\
Skewness & -.271 \\
Std. Error of Skewness & .185 \\
Kurtosis & -1.949 \\
Std. Error of Kurtosis & .367 \\
Minimum & 1 \\
Maximum & 2 \\
\hline
\end{tabular}

Source: data processing by the authors, SPSS

Table 4. Frequency Table - Gen

\begin{tabular}{|c|c|c|c|c|}
\hline Valid & Frequency & Percent & Valid Percent & Cumulative Percent \\
Male & 75 & 43.4 & 43.4 & 43.4 \\
Female & 98 & 56.6 & 56.6 & 100.0 \\
Total & 173 & 100.0 & 100.0 & \\
\hline
\end{tabular}

Source: data processing by the authors, SPSS

\subsection{Analysis of the dimensionality, validity and fidelity of the construct scale}

Formally, the 12 items that make up the ,individual expectations" scale lend themselves to a simple construction of indices by adding the scores by items. However, in order to build an index of the scale, it is necessary to ensure that the scale is unidimensional and precise.

On the other hand, thinking of the subjective nature of measurement in social and human sciences that cannot compare with measurements in exact sciences (since social phenomena cannot be measured directly, but through observable indicators which we only assume to be related to the investigated phenomenon) a natural question arises: Do the indicators that we are using really represent the studied phenomenon? And if so, how precisely do they represent it? The answer is given by the analysis of validity and fidelity 
(Opariuc, D., 2009, pp. 283). From the statistical point of view, this type of analysis helps us eliminate the two sources of error: random errors (influences of external factors that can affect the measurements) and non-random or systematic errors, which have a constant character and, most of the time, are related to the research instrument.

The validity of the scale we have created to define the individual expectations construct, as a research tool, takes into account the fact that the 12 items that make up the scale can measure what they are intended to measure, namely the expectations individuals have from the community in which they live. Fidelity, on the other hand, starts from the assumption that the items are already measuring the investigated dimension, and tries to determine how precisely and how reliably they do this (Şandor, D.S., 2012, pp. 26).

\subsubsection{Unidimensionality analysis}

Fidelity does not inform us about the unidimensionality of a scale, but about how the scale items are related to each other (Opariuc, D., 2011, pp. 372).

The unidimensionality of the scale is achieved through factor analysis - the principal components method (Hatos, A., 2010, pp.80). From the result in SPSS, we will retain the Total V ariance Explained table, showing the synthesis of:

a. Component - The initial number of factors, corresponding to the number of scale items. (http://www.ats.ucla.edu/stat/spss/output/factor1.htm, accessed on 09.04.2016, at 9.30 a.m.);

b. Initial Eigenvalues - eigenvalues of factors variance. Factor analysis is performed on the correlation matrix of standardized variables, the result being that each variable has a variation of 1 , the total variance is equal to the number of variables used in the analysis;

c. Total (eigenvalues). The first factor shows the highest variance and has the highest eigenvalues; each successive factor will have increasingly smaller values.

d. Extraction Sums of Squared Loadings - corresponds to the number of extracted factors. The values of the factors (items) extracted is calculated similarly to point $\boldsymbol{b}$ ), except that here the values are based on common variance, which is always smaller than the total variance.

In Table 5 we may see that, except for one factor, no other factor explains more than the variance of a single variable (all eigenvalues are smaller than 1, with the exception of the first component).

This result suggests that the scale consisting of 12 items is unidimensional. Factor 1, which was extracted, explains $62.24 \%$ of the variance of the 12 items (Hatos, A., 2010, pp.84).

Table 5. Total Variance Explained

\begin{tabular}{|c|c|c|c|c|c|c|}
\hline \multirow{2}{*}{ Component } & \multicolumn{3}{|c|}{ Initial Eigenvalues } & \multicolumn{3}{c|}{ Extraction Sums of Squared Loadings } \\
\cline { 2 - 6 } & Total & $\begin{array}{c}\% \text { of } \\
\text { Variance }\end{array}$ & $\begin{array}{c}\text { Cumulative } \\
\%\end{array}$ & Total & $\%$ of Variance & $\begin{array}{c}\text { Cumulative } \\
\%\end{array}$ \\
\hline 1 & 7.469 & 62.242 & 62.242 & 7.469 & 62.242 & 62.242 \\
2 & .963 & 8.027 & 70.269 & & & \\
3 & .780 & 6.503 & 76.772 & & & \\
4 & .592 & 4.929 & 81.701 & & &
\end{tabular}




\begin{tabular}{|c|c|c|c|c|c|c|}
\hline \multirow{2}{*}{ Component } & \multicolumn{3}{|c|}{ Initial Eigenvalues } & \multicolumn{3}{|c|}{ Extraction Sums of Squared Loadings } \\
\cline { 2 - 7 } & Total & $\begin{array}{c}\% \text { of } \\
\text { Variance }\end{array}$ & $\begin{array}{c}\text { Cumulative } \\
\%\end{array}$ & Total & $\%$ of Variance & $\begin{array}{c}\text { Cumulative } \\
\%\end{array}$ \\
\hline 6 & .377 & 3.144 & 88.678 & & & \\
7 & .335 & 2.788 & 91.466 & & & \\
8 & .292 & 2.429 & 93.895 & & & \\
9 & .235 & 1.962 & 95.857 & & & \\
10 & .182 & 1.520 & 97.378 & & & \\
11 & .174 & 1.446 & 98.824 & & & \\
12 & .141 & 1.176 & 100.000 & & & \\
\hline
\end{tabular}

Extraction Method: Principal Component Analysis.

Source: data processing by the authors, SPSS

\subsubsection{Reliability analysis}

Reliability analysis starts from the fact that the result obtained after a measurement contains the real score and the amount of random errors, according to the formula:

$\boldsymbol{X}=\boldsymbol{t}+\boldsymbol{e}, \quad$ where $\boldsymbol{t}=$ real score, and $\boldsymbol{e}=$ amount of random errors

Fidelity can be measured in several ways: test / retest, parallel forms, internal consistency. Choosing one of these fidelity indicators for the attenuation correction of errors is still the subject of scientific analysis and dispute. Cronbach argued the need to define a single fidelity indicator, which should allow for comparing certain corrected correlations using different methods; for this purpose, he defined the alpha Cronbach reliability coefficient (Popa, M. 2011, pp.3).

The alpha Cronbach coefficient of internal consistency may normally take values between $\boldsymbol{O}$ and $\mathbf{1}$; the $\boldsymbol{O}$ value indicates that the instrument only measured random errors, having nothing to do with the real score and, a value of 1 indicates that the instrument measures only the real score, the random errors having been completely eliminated. In extreme cases, it is possible to obtain higher values than 1 or negative values. These situations usually occur when the data contains errors, the sample is very small or the number of items is very low (Popa, M., 2011, pp. 85).

Further on we will study reliability through internal consistency, calculating the internal consistency of the "Alpha (Cronbach)" coefficient according to the formula: (Popa, M., 2011, pp.4):

$$
\alpha=\frac{N * r m}{1+(N-1) * r m} \begin{aligned}
& \text { where: } \mathrm{N}=\text { number of items; } \\
& \text { rm }=\text { average of correlation coefficient between } \\
& \text { items. }
\end{aligned}
$$

In the study that we are performing we have chosen to analyze the fidelity of the 12 item „individual expectations" scale, being stimulated by the statement of Cronbach Lee, father of the alpha coefficient of internal consistency: „Even those investigators who regard reliability as a pale shadow of the more vital matter of validity cannot avoid considering the reliability of their measurements. No validity coefficient and no factor analysis can be interpreted without some appropriate estimate of the magnitude of the error of measurement" (Cronbach, 1951, pp.179). 
The Cronbach alpha (a) coefficient is an indicator of the accuracy of measurement of the internal consistency and reliability of the ,individual expectations" scale, because of its specificity as an index or coefficient which measures the internal consistency characteristic of a psychological tool consisting of several items that are added up in a single score. For reliability analysis, we are interested in the subjects' responses to each item and not in the raw scores obtained on the scale or at the entire questionnaire level (Opariuc, D., 2009, pp.315).

The study of internal consistency for the „individual expectations" scale was performed on a total of 173 subjects, without cases excluded from the analysis, all with correctly completed results, the percentage of valid results being 100\% (Table 6). The confidence interval for which the analysis is carried out is $95 \%$.

Table 6. Case Processing Summary

\begin{tabular}{|ll|c|c|}
\hline & $\mathrm{N}$ & $\%$ \\
\hline \multirow{3}{*}{ Cases } & Valid & 173 & 100.0 \\
& Excluded $^{\mathrm{a}}$ & 0 & .0 \\
& Total & 173 & 100.0 \\
\hline
\end{tabular}

a. Listwise deletion based on all variables in the procedure.

Source: data processing by the authors, SPSS

\subsubsection{Algorithm to verify the reliability of the scale}

a) The Cronbach $\alpha$ internal consistency coefficient of the 12 item scale has an almost equal value (0.942) both in raw form and in standardized form (Table 7). The coefficient values around 0.90 are considered to be „excellent”, the ones around 0.80 , „very good”, while the ones around 0.70, ,adequate” (Popa, M., 2011, pp .4). In our case, the coefficient value (0.942) indicates that the „individual expectations" scale is accurate in terms of internal consistency.

Table 7. $\alpha$ Cronbach Internal consistency coefficient. Reliability Statistics

\begin{tabular}{|c|c|c|}
\hline Cronbach's Alpha & Cronbach's Alpha Based on Standardized Items & N of Items \\
\hline 0.942075 & 0.941144 & 12 \\
\hline
\end{tabular}

Source: data processing by the authors, SPSS

b) The descriptive statistics for each analysed item (mean and standard deviation) suggest that the means are approximately equal, with no significant differences between them (Table 8).

Also as part of the descriptive analysis of each item, we would like to find out more about the extent to which the answers are grouped or scattered across the range of possible answers (on the scale of answers from 1 to 5 - 1 being very small, and 5 very high). For this purpose, we will calculate the interquartiles (IQR) as a measure of dispersion (the defined scale has the median score 3). A relatively low score of IQR is an indication of consensus. By contrast, a higher score of IQR might suggest that the opinions are polarized, namely, that the respondents tend to have strong opinions, favourable or not to the topic under investigation (http://achilleaskostoulas.com/2014/02/23/how-to-interpret-ordinal-data/, accessed on 18.02.2016, at 9.30 a.m.). 
In our case, an analysis of Table 8 indicates that two of the items have the score IQR $=2$ (the need to be encouraged and the need to be cared for), the remaining items having the score 1 , while the score of the median is 3 , as we have already mentioned.

The calculated values suggest that most of the respondents seem to think that there is a very low probability (mean of the construct $=2.693-$ see table 12 ) that the community response to their individual needs (individual expectations, as defined by the scale items) would be at least satisfactory.

Table 8. Item Statistics

\begin{tabular}{|c|c|c|c|c|}
\hline & Mean & Std. Deviation & IQR & N \\
\hline accepted & 2.90 & .962 & 1 & 173 \\
understood & 2.64 & .882 & 1 & 173 \\
admired & 2.54 & .955 & 1 & 173 \\
confirmed & 2.64 & .927 & 1 & 173 \\
recognized & 2.69 & .899 & 1 & 173 \\
secure & 3.24 & .736 & 1 & 173 \\
approved & 2.60 & .813 & 1 & 173 \\
encouraged & 2.34 & .984 & 2 & 173 \\
respected & 2.90 & .965 & 1 & 173 \\
credible & 2.75 & 1.012 & 1 & 173 \\
appreciated & 2.71 & 1.000 & 1 & 173 \\
cared for & 2.39 & 1.059 & 2 & 173 \\
\hline
\end{tabular}

Source: data processing by the authors, SPSS

At scale level, the descriptive statistics indicate that the 12 item ,individual expectations" scale, has an average of 32.32 points, with a standard deviation of 8.787 points (table 9).

Table 9. Scale Statistics

\begin{tabular}{|c|c|c|c|}
\hline Mean & Variance & Std. Deviation & N of Items \\
\hline 32.32 & 77.218 & 8.787 & 12 \\
\hline
\end{tabular}

Source: data processing by the authors, SPSS

c) Correlation and covariance matrices are shown in Tables 10 and 11. The correlation coefficients between the 12 items have high values, which explains the high scale fidelity obtained. Relatively small values (compared to the rest of scale items) are registered for the secure item. Even in this case, one can notice that there are no negative relationships among the items (which would have indicated a possible problem with the construction of the respective items) or extremely high values, close to 1 , which could suggest that the respective items have an excessive degree of similarity, their use in the same scale not being justified (Popa, M., 2014, pp.14).

Table 10. Inter-Item Correlation Matrix

\begin{tabular}{|l|c|c|c|c|c|c|c|c|c|c|c|c|}
\hline & accepted & understood & admired & confirmed & recognized & secure & approved & encouraged & respected & credible & appreciated & cared for \\
\hline accepted & 1.000 & .698 & .639 & .658 & .616 & .255 & .588 & .483 & .609 & .565 & .592 & .442 \\
understood & .698 & 1.000 & .637 & .589 & .576 & .364 & .721 & .575 & .578 & .609 & .644 & .498 \\
admired & .639 & .637 & 1.000 & .685 & .677 & .148 & .619 & .500 & .629 & .662 & .684 & .494 \\
confirmed & .658 & .589 & .685 & 1.000 & .820 & .253 & .709 & .534 & .680 & .679 & .707 & .527 \\
recognized & .616 & .576 & .677 & .820 & 1.000 & .270 & .733 & .552 & .679 & .687 & .737 & .524
\end{tabular}




\begin{tabular}{|l|c|c|c|c|c|c|c|c|c|c|c|c|}
\hline & accepted & understood & admired & confirmed & recognized & secure & approved & encouraged & respected & credible & appreciated & cared for \\
\hline secure & .255 & .364 & .148 & .253 & .270 & 1.000 & .384 & .291 & .297 & .259 & .253 & .172 \\
approved & .588 & .721 & .619 & .709 & .733 & .384 & 1.000 & .672 & .658 & .689 & .711 & .568 \\
encouraged & .483 & .575 & .500 & .534 & .552 & .291 & .672 & 1.000 & .594 & .598 & .662 & .672 \\
respected & .609 & .578 & .629 & .680 & .679 & .297 & .658 & .594 & 1.000 & .813 & .800 & .563 \\
credible & .565 & .609 & .662 & .679 & .687 & .259 & .689 & .598 & .813 & 1.000 & .754 & .573 \\
appreciated & .592 & .644 & .684 & .707 & .737 & .253 & .711 & .662 & .800 & .754 & 1.000 & .597 \\
cared for & .442 & .498 & .494 & .527 & .524 & .172 & .568 & .672 & .563 & .573 & .597 & 1.000 \\
\hline
\end{tabular}

Source: data processing by the authors, SPSS

The covariance coefficients (Table 11) indicate the scale homogeneity. The differences between the items are relatively small, the surveyed subjects responding in a compact manner on the "individual expectations" scale; from this we deduce that the scale reliability has a high value.

Table 11. Inter-Item Covariance Matrix

\begin{tabular}{|l|c|c|c|c|c|c|c|c|c|c|c|c|}
\hline & accepted & understood & admired & confirmed & recognized & secure & approved & encouraged & respected & credible & appreciated & cared for \\
\hline accepted & .926 & .592 & .588 & .587 & .533 & .180 & .460 & .458 & .565 & .551 & .570 & .451 \\
understood & .592 & .778 & .537 & .481 & .457 & .237 & .517 & .499 & .492 & .544 & .568 & .465 \\
admired & .588 & .537 & .913 & .607 & .582 & .104 & .480 & .470 & .580 & .640 & .654 & .500 \\
confirmed & .587 & .481 & .607 & .859 & .684 & .173 & .534 & .487 & .608 & .637 & .655 & .518 \\
recognized & .533 & .457 & .582 & .684 & .809 & .179 & .536 & .489 & .589 & .625 & .663 & .499 \\
secure & .180 & .237 & .104 & .173 & .179 & .542 & .230 & .211 & .211 & .193 & .187 & .134 \\
approved & .460 & .517 & .480 & .534 & .536 & .230 & .661 & .538 & .516 & .567 & .578 & .489 \\
encouraged & .458 & .499 & .470 & .487 & .489 & .211 & .538 & .968 & .564 & .595 & .652 & .701 \\
respected & .565 & .492 & .580 & .608 & .589 & .211 & .516 & .564 & .931 & .794 & .771 & .575 \\
credible & .551 & .544 & .640 & .637 & .625 & .193 & .567 & .595 & .794 & 1.025 & .764 & .614 \\
appreciated & .570 & .568 & .654 & .655 & .663 & .187 & .578 & .652 & .771 & .764 & 1.000 & .632 \\
cared for & .451 & .465 & .500 & .518 & .499 & .134 & .489 & .701 & .575 & .614 & .632 & 1.122 \\
\hline
\end{tabular}

Source: data processing by the authors, SPSS

d) Correlative statistics. In Table 12 we can notice that in the mean column the average of the means of the 12 items is 2.693 , being situated between a minimum of 2.335 and a maximum of 3.237. The amplitude between the lowest and the highest average is only 0.902 , while the variance of the means is very low (0.059). We can observe the same trends in the analysis of the variance, as well as when we study the covariances and correlations in a synthesized manner.

Table 12. Summary Item Statistics

\begin{tabular}{|l|c|c|c|c|c|c|c|}
\hline & Mean & Minimum & Maximum & Range & $\begin{array}{c}\text { Maximum } \\
\text { Minimum }\end{array}$ & Variance & N of Items \\
\hline Item Means & 2.693 & 2.335 & 3.237 & .902 & 1.386 & .059 & 12 \\
Item Variances & .878 & .542 & 1.122 & .580 & 2.070 & .026 & 12 \\
Inter-Item Covariances & .505 & .104 & .794 & .689 & 7.602 & .026 & 12 \\
Inter-Item Correlations & .571 & .148 & .820 & .672 & 5.528 & .025 & 12 \\
\hline
\end{tabular}

Source: data processing by the authors, SPSS

Table 13 examines the parameters of the scale in case any of the 12 items is eliminated. The corrected value (Corrected Item-Total Correlation) indicates the correlation between each item and the total score of the questionnaire. On a reliable scale, all the items should be correlated with the total scale score. In our case, we note that there are no values lower than 0.3 , which could suggest a possible mismatch of one of the items on the scale 
(Field, A., 2006, pp. 3). Assuming that any of the items can be removed, we also note that the recalculated Alpha index is quite close to the originally calculated values (Alpha $=0.942$ and Standardized Items Alpha $=0.941)$. In the analysis we are performing we are interested in those Alpha indices that have higher values than the initial ones, since they could lead to greater internal consistency of the scale. None of the items in Table 13 would substantially affect the scale reliability, if they were deleted. The biggest „disruptive" element is the secure item which, if removed, would increase the Alpha value from 0.942 to 0.949 (by only 0.007 points).

Finally, we can conclude that the ,individual expectations" scale has a good internal consistency, $\alpha=0.94$, meaning that all the items could be kept.

Table 13. Item-Total Statistics

\begin{tabular}{|l|c|c|c|c|c|}
\hline & $\begin{array}{c}\text { Scale Mean if } \\
\text { Item Deleted }\end{array}$ & $\begin{array}{c}\text { Scale Variance } \\
\text { if Item Deleted }\end{array}$ & $\begin{array}{c}\text { Corrected Item- } \\
\text { Total Correlation }\end{array}$ & $\begin{array}{c}\text { Squared Multiple } \\
\text { Correlation }\end{array}$ & $\begin{array}{c}\text { Cronbach's Alpha } \\
\text { if Item Deleted }\end{array}$ \\
\hline accepted & 29.42 & 65.221 & .712 & .614 & .938 \\
understood & 29.68 & 65.662 & .754 & .679 & .937 \\
admired & 29.78 & 64.824 & .746 & .628 & .937 \\
confirmed & 29.68 & 64.418 & .803 & .740 & .935 \\
recognized & 29.63 & 64.734 & .807 & .750 & .935 \\
secure & 29.08 & 72.598 & .325 & .215 & .949 \\
approved & 29.72 & 65.667 & .827 & .732 & .935 \\
encouraged & 29.98 & 64.924 & .714 & .609 & .938 \\
respected & 29.42 & 63.757 & .813 & .760 & .934 \\
credible & 29.57 & 63.142 & .811 & .731 & .934 \\
appreciated & 29.61 & 62.832 & .844 & .762 & .933 \\
cared for & 29.93 & 64.937 & .654 & .518 & .941 \\
\hline \multicolumn{5}{|l|}{ Alpha $=0.942075$} & \multicolumn{3}{|c|}{ Standardized Items Alpha = } & 0.941144 \\
\hline
\end{tabular}

Source: data processing by the authors, SPSS

e) Testing the equality of the means. The equality of the means was checked by performing the Hotelling's T-Square test, starting from the null hypothesis according to which the means of the scale items are equal (Table 14). The values in Table 14 indicate that the test is significant; we would have been wrong if we had assumed that the means of each of the 12 items were equal (tabular critical value, $F_{(11.162)}=2.185$, for $\mathrm{p}<0.01$; $F$ $=17.653>2.185)$. The values obtained allow us to affirm that there are significant differences between the subjects' answers to this set of questions, thereby the necessary variability and heterogeneity being ensured.

Table 14. Hotelling's T-Squared Test

\begin{tabular}{|c|c|c|c|c|}
\hline Hotelling's T-Squared & F & df1 & df2 & Sig \\
\hline 206.165 & 17.653 & 11 & 162 & .000 \\
\hline
\end{tabular}

Source: data processing by the authors, SPSS

\subsubsection{Validity analysis}

The documentary research that we did both prior to starting the study and during the drafting of the paper revealed that there are very few scientific papers 
addressing the topic of the relations established between the individuals and the community. Specifically, as shown in Table 15, a search on Google Scholar allowed us to identify 11 papers published in Romania, tackling various aspects of the relations established between individuals, in terms of individual expectations and 15.400 papers published in the world (an extremely small number if we consider the study area). Even so, most of these papers deal with other fields of study than the socio-economic one.

Although initially the psychologists were the ones concerned to create a construct as a measurement instrument, in recent years more and more researchers in the social and human sciences use this instrument. Thus, papers have appeared aiming to assess the organizational climate (Ticu, C., 2008, pp. 16), or, more recently, to establish a performance scale of social economy enterprises (Peng, L., \& Liang, C., 2016, pp. 3), to mention just two significant examples for our study.

Generally, certifying the validity of the instrument we use requires the certification of construct validity, theoretical validity and content validity (http://www.schuhfried.ro Lmeta-navigation/noutati/details//artikel/validitatea-734/, accessed on 02.28.2016, $10.30 \mathrm{am})$.

Construct validity contains the empirical evidence and arguments which prove the correctness of the test results' interpretation in the sense of explanatory concepts.

The theoretical validity refers to performing a specialized synthesis of the scientific papers, leading to the formulation of a theoretical model of a scale.

Content validity refers to how the items are suitable to measure the construct.

In our case, the items that we used in building the individual expectations scale define the basic needs of every individual; it is well known that the relationships established between individuals have a highly subjective character, which often starts from the degree to which their individual expectations are fulfilled. From this perspective, we considered that the introduction of unanimously recognized and accepted basic needs in the individual expectations scale construct validates the contents of this scale, the items being suitable to measure the construct.

The subject of the construct validity is as controversial as it is sensitive, so that for now we will only consider that the scale we have defined fulfils the validity condition. It is clear, however, that we have opened a field of study which in the future can confirm our claim or not.

Table 15. Scientific studies regarding the surveyed topic

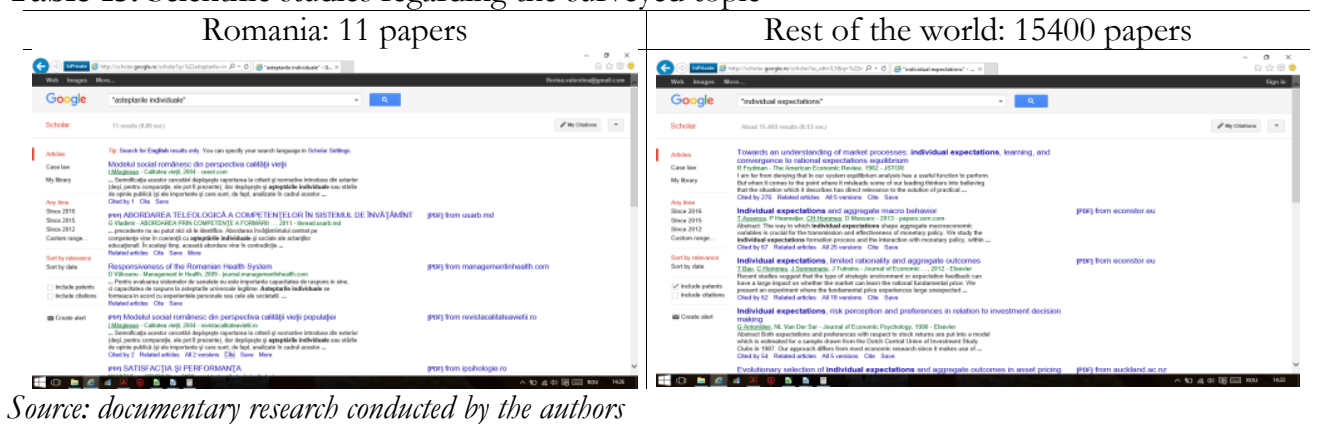




\subsection{Testing the work hypotheses}

In order to achieve the main objective of this paper, which is closely related to the dilemma that we have about the existence of conditionality between the expectations that the surveyed subjects have from their community and their availability to work for the community benefit, we have formulated the following hypotheses, tested later in the IBM SPSS and Microsoft Excel applications:

The null hypothesis (HO): there is no relationship between the individual expectations that the surveyed subjects have from their communities and their decision to support the community.

The alternative hypothesis (H1): there is a significant relationship between the individual expectations that the surveyed subjects have from their communities and their decision to support the community.

The variables are nominal, or treated as a nominal scale, so we checked the assumptions by calculating the correlation coefficients established between variables, for each item of the individual expectations scale (Table 16) and for the full scale (Table 17), after having previously calculated the weighted statistical mean of the items at scale level using the IBM SPSS application.

The results presented in Tables 16 and 17 highlight, for both working versions, negative values of the correlations both at item level and at the whole scale level. Therefore, we cannot reject the null bypothesis, according to which there is no relationship between the individual expectations that the participants in the study have from their communities and their decision to support the community.

\begin{tabular}{|c|c|c|c|c|c|c|c|c|c|c|c|c|c|}
\hline Correlations & accepted & understo adm & mired & confryed & recognized & sacurely & approved & encouraged res & pected & credible & appreciate c & cared & ActionC \\
\hline accepted & 1.000 & & & & & & & & & & & & \\
\hline understood & 0.008 & 1.000 & & & & & & & & & & & \\
\hline admired & 0.639 & 0.637 & 1.000 & & & & & & & & & & \\
\hline confimed & 0.658 & 0.589 & 0.685 & 1.000 & & & & & & & & & \\
\hline recognized & 0.616 & 0.576 & 0.677 & 0.820 & 1.000 & & & & & & & & \\
\hline securely & 0.255 & 0.364 & 0.148 & 0.253 & 0.270 & 1.000 & & & & & & & \\
\hline approved & 0.588 & 0.721 & 0.619 & 0.709 & 0.733 & 0.384 & 1.000 & & & & & & \\
\hline encouraged & 0.483 & 0.575 & 0.500 & 0.534 & 0.552 & 0.291 & 0.672 & 1.000 & & & & & \\
\hline respected & 0.609 & 0.578 & 0.620 & 0.680 & 0.679 & 0.297 & 0.658 & 0.594 & 1.000 & & & & \\
\hline credible & 0.565 & 0.609 & 0.602 & 0.679 & 0.687 & 0.259 & 0.689 & 0.598 & 0.813 & 1.000 & & & \\
\hline appreciated & 0.592 & 0.644 & 0.684 & 0.707 & 0.737 & 0.253 & 0.711 & 0.602 & 0.800 & 0.734 & 1.000 & & \\
\hline cared & 0.442 & 0.498 & 0.494 & 0.52 & 0.524 & 0.172 & 0.568 & 0.672 & 0.563 & 0.573 & 0.597 & 1.000 & \\
\hline ActionC & -0.082 & -0.103 & -0.037 & -0.085 & -0.133 & -0.076 & -0.091 & -0.100 & -0.139 & -0.158 & -0.018 & -0.053 & 1.000 \\
\hline
\end{tabular}

Source: data processing, by the authors, in Microsoft Excel

$\begin{aligned} & \text { Table 17. The correlation between "ActionC" } \\
& \text { variable and the weighted statistical average } \\
& \text { of the scale items }\end{aligned}$
\begin{tabular}{llr} 
Correlations & ActionC & Expectations \\
Actionc & 1 & 1 \\
Expectations & -0.0562304675 & 1 \\
\hline
\end{tabular}


In order to verify the result, we studied the frequency of responses received from the surveyed subjects (Table 18) and non-parametric correlation coefficients, derived from chi square.

The variables analysed are: the 12 variables that define the scale items (independent variables) and the Action $C$ variable (dependent variable). As expected, the calculated threshold value, 0.879 (Table 18), is higher than the accepted threshold, 0.05, so that not in this variant either can we reject the null hypothesis; the individual expectations that the surveyed subjects have from their community do not influence their decision to support the community.

\section{Table 18. ActionC * Expectations Crosstabulation}

Count

\begin{tabular}{|l|c|c|c|c|c|c|}
\hline \multirow{2}{*}{ ActionC } & \multicolumn{4}{|c|}{ Expectations } & \\
\cline { 2 - 7 } & very & low & moderate & high & $\begin{array}{c}\text { very } \\
\text { high }\end{array}$ & Total \\
\hline The community can manage very well, without me & 4 & 16 & 56 & 13 & 1 & 90 \\
I would first ask why my involvement is so necessary & 0 & 4 & 8 & 2 & 1 & 15 \\
I would let other people get involved first, and & 0 & 0 & 3 & 0 & 0 & 3 \\
afterwards I would act & 4 & 13 & 35 & 10 & 0 & 62 \\
I would first check the veracity of the information & 0 & 1 & 2 & 0 & 0 & 3 \\
I would engage without hesitation & 8 & 34 & 104 & 25 & 2 & 173 \\
Total & & & &
\end{tabular}

\section{Symmetric Measures}

\begin{tabular}{|c|c|c|c|}
\hline $\begin{array}{l}\text { Nominal by Nominal } \\
\text { N of Valid Cases }\end{array}$ & |Contingency Coefficient & $\begin{array}{c}\text { Value } \\
.231 \\
173\end{array}$ & $\begin{array}{c}\text { Approx. Sig. } \\
.879\end{array}$ \\
\hline
\end{tabular}

a. Not assuming the null hypothesis.

b. Using the asymptotic standard error assuming the null hypothesis.

Source: data processing by the authors, SPSS

To achieve the secondary objective of the study, we have analysed the frequency of the responses received to the question (combined with the analysis of the correlation or association coefficients, as the situation requires): „Assuming you were asked today to support the community in which you live, how would you act? With the following answers: 1 . I would engage without hesitation; 2. I would first ask why my involvement is so necessary; 3. I would let other people get involved first, and afterwards I would act; 4. I would first check the veracity of the information; 5. The community will be able to manage very well, without me", for which we formulated the following work assumptions (tested in the IBM SPSS application):

The null hypothesis (HO): the response options are equally preferred by the surveyed subjects.

The alternative hypothesis (H1): a particular variant of answer is preferred by the surveyed subjects.

The two variables analysed are: biological gender - independent variable and actionC dependent variable.

The results obtained in Table 19 suggests that the availability of the study participants to get involved in community activities is rather low, $52 \%$ of them considering that the 
community is able to manage just as well without their support and, only $48 \%$ of them appear to have some degree of interest to get involved in community affairs.

The variables analysed are nominal, or treated as nominal scales, therefore the working assumptions were verified by calculating the parametric correlation coefficients and, to verify the result we proceeded in a similar way as with the previous model, by calculating the non-parametric correlation coefficients derived from chi square.

The results presented in Table 20 highlight again negative correlations $(-0.131)$ between the two variables: biological gender $(G e n B)$ and Action $C$, which suggests that not in this case either can the null hypothesis be rejected, which is confirmed in fact by the values obtained for the non-parametric correlation coefficients derived from chi-square.

Table 19. GenB * ActionC Crosstabulation

\begin{tabular}{|l|c|c|c|c|c|c|}
\hline \multirow{2}{*}{ Count } & \multicolumn{5}{|c|}{ ActionC } & Total \\
\cline { 2 - 7 } & $\begin{array}{c}\text { The community } \\
\text { will be able to } \\
\text { manage very } \\
\text { well, without } \\
\text { me }\end{array}$ & $\begin{array}{c}\text { I would first ask } \\
\text { why my } \\
\text { involvement is } \\
\text { so necessary }\end{array}$ & $\begin{array}{c}\text { I would let } \\
\text { other people get } \\
\text { involved first, } \\
\text { and afterwards I } \\
\text { would act }\end{array}$ & $\begin{array}{c}\text { I would first } \\
\text { check the } \\
\text { veracity of the } \\
\text { information }\end{array}$ & $\begin{array}{c}\text { I would } \\
\text { engage } \\
\text { without } \\
\text { hesitation }\end{array}$ & \\
\hline GenB & 32 & 10 & 0 & 31 & 2 & 75 \\
Total & 58 & 5 & 3 & 31 & 1 & 98 \\
Fale & Female & 15 & 3 & 62 & 3 & 173 \\
\hline
\end{tabular}

Source: data processing by the authors, SPSS

The calculated values of the significance threshold $(0.879 ; 0.635 ; 0.979$, etc, see Table 21$)$ exceed by far the accepted threshold, 0.05 , so that neither in this variant can we reject the null hypothesis; despite the appearances, the preference of the surveyed subjects to support the community, at the time of the survey, is not well-defined (Figure 1).

Table 20. Correlations

\begin{tabular}{|ll|c|c|}
\hline \multirow{4}{*}{ GenB } & Pearson Correlation & GenB & ActionC \\
& Sig. (2-tailed) & 1 & -.131 \\
& $\mathrm{~N}$ & & .087 \\
& Pearson Correlation & 173 & 173 \\
\multirow{4}{*}{ ActionC } & Sig. (2-tailed) & -.131 & 1 \\
& $\mathrm{~N}$ & .087 & \\
& & 173 & 173 \\
\hline
\end{tabular}

Source: data processing by the authors, SPSS

Table 21. Symmetric Measures

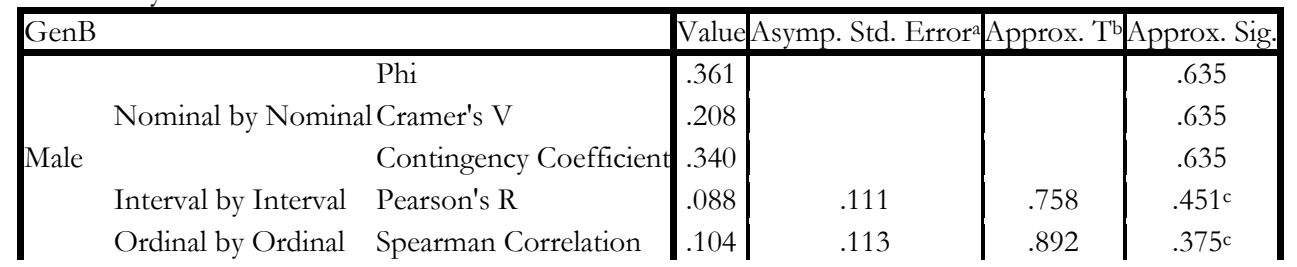




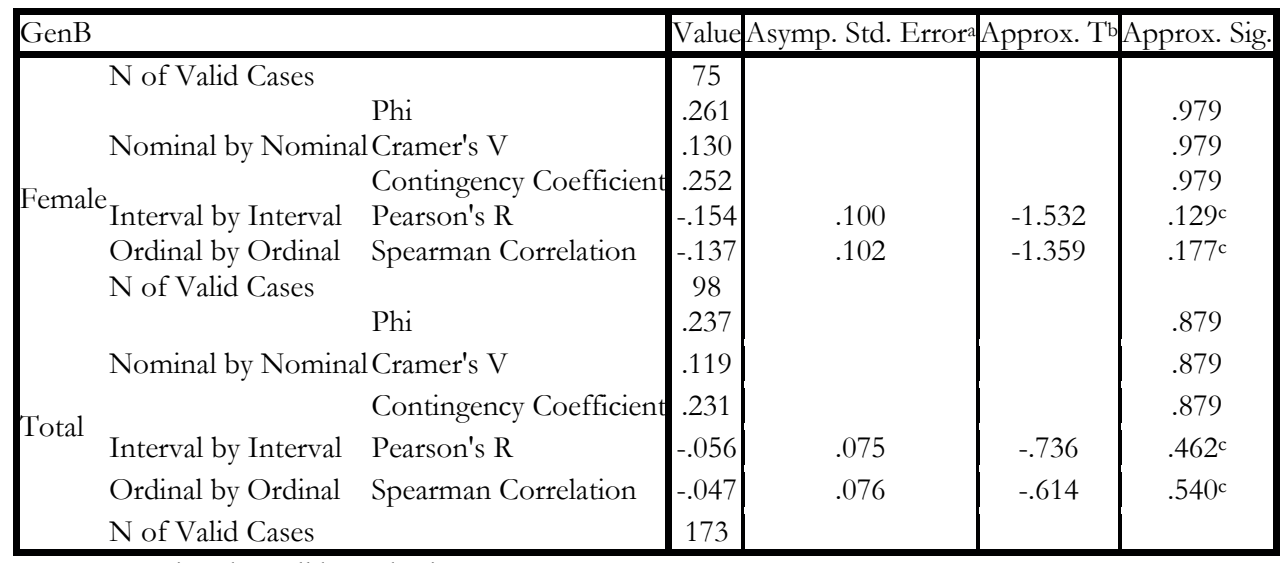

a. Not assuming the null hypothesis.

b. Using the asymptotic standard error assuming the null hypothesis.

c. Based on normal approximation.

Source: data processing by the authors, SPSS

The graph in Figure 1 indicates that only 3 of the survey participants (two men and one woman) are willing to respond with the highest celerity to the community need to be supported, while most of them (90 subjects, of which 32 men and 58 women, representing $52 \%$ of the surveyed subjects) categorically feel that their involvement in community activities is totally inadequate, because the community can manage just as well without their support. Between these two extremes there is a wide enough range of sceptics who oscillate between: first check the veracity of the information (62 people, including 31 men and 31 women); asking why their involvement was necessary (15 people, including 10 men and 5 women); or, would let other people get involved and after that they would act, a category in which we identified three women.

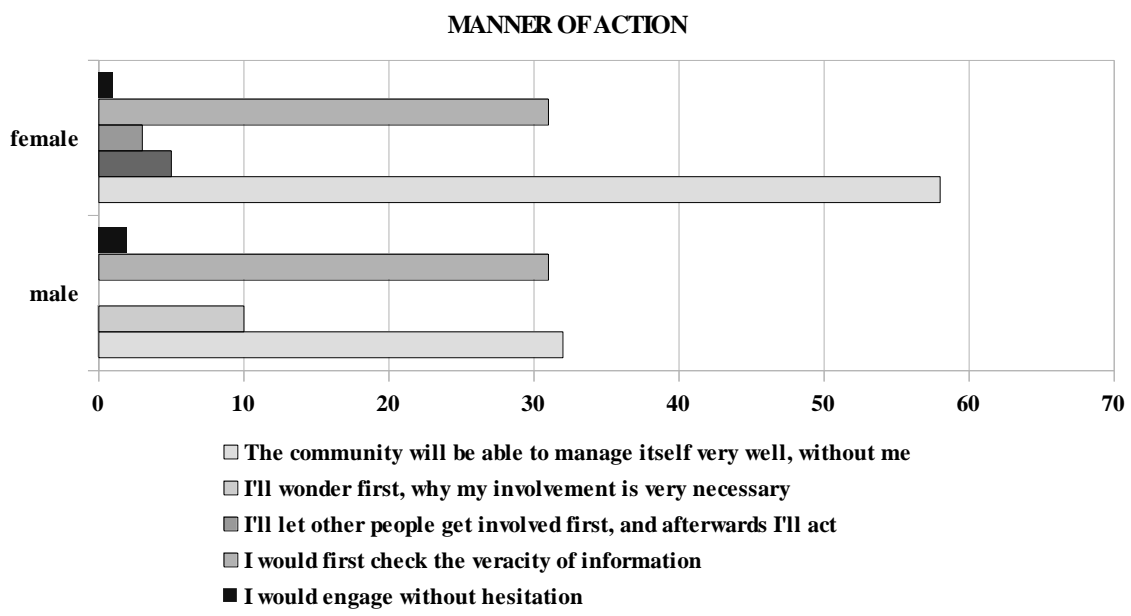

Figure 1. The availability of the surveyed subjects to act for the benefit of the community

Source: data processing by the authors, SPSS 


\section{Conclusions}

The results of the investigation, obtained after testing the assumptions, indicate that the individual expectations which the surveyed subjects have from their community do not influence their decision to get involved (in any way) in the community, there being no conditioning between the two ,elements of the equation”.

The preference of the surveyed subjects to act for the benefit of the community, at the time of the survey, is not sufficiently well defined. Moreover, the surveyed subjects seem to think that the degree to which the community meets their basic needs (as defined by the individual expectations construct) is very low. On the other hand, the responses received from the surveyed subjects suggest low social cohesion, lack of comprehension of the individuals of the community problems and a low ability to empathize with the specific problems of their communities.

The documentary research that we carried out, both prior to the beginning of the study and during the drafting of the paper has revealed that there are very few scientific papers, of an applicative nature, addressing the topic of the relations established between the individuals and the community, in the light of expectations that the individuals have from their community. Specifically, as shown in Table 15, a search on Google Scholar allowed us to identify 11 papers with similar approaches published in Romania and 15.400 papers published worldwide (an extremely small number if we consider the study area and the importance of the subject). Even so, most of these papers deal with other fields of study than the socio-economic one.

From this perspective, our paper contributes to the development of knowledge as a pioneering one in the socio-economic research, with applicability to local communities. Thus, we have opened a gateway towards interdisciplinary research, with applicability in the sphere of the relationships that are established in local communities.

The construct which we used as a tool to measure the perceptions of the surveyed subjects regarding the extent to which the community responds to their individual needs can be used in the future in similar research and, in combination with the constructs tailored to the specific objectives of the new research studies, it may be adapted to measure certain variables / parameters defining the community: mutual trust, community cohesion and how this affects the quality of life, relationships, attitudes, values that govern the human interactions, thus contributing to the economic and social development of the community, etc.

We consider that we have eliminated from the beginning the sources of error that could come from misunderstanding the questions, because throughout the investigation we interacted directly with the surveyed subjects, as follows: a part of the questionnaires were directly distributed, printed on paper and completed in our presence; the online questionnaire contains our contact details which can be used to call us to clarify any possible misunderstanding. We are making this clarification because most of the answers to the questions that define the individual expectations scale scored around point 3, which coincides with the scale median; this would suggest that the response might be elusive or that the meaning of the question was not sufficiently well understood. As a consequence, this could be a possible limitation of the study, for the elimination of which we propose that future studies should use a Likert scale with 6 or 8 points, so that the reply option would 
avoid the median score of the scale.

Another limitation of the study can arise from the fact that there is little information that may help validate the construct of individual expectations. To eliminate this drawback, future studies should include a larger number of participants (or target structurally and territorially well-defined communities), use a Likert scale with an even number of points $(6,8$ or 10$)$ and be supplemented with qualitative information that can highlight the biunivocal nature of the relationships in the community, such as, for example, systematic observation of the activities in the community.

In the future, we intend to develop the study using two distinct approaches: 1) We will analyse, through reciprocity, if there is any conditioning between the community expectations (needs) and the individuals' availability to support the community; 2) we will analyse the characteristics of communities, in ways that are not based on the aggregation of responses of individuals, such as: observable characteristics of a community through indicators of reciprocity (e.g.: the extent to which public spaces are cleaned), or indicators of confidence (e.g.: are services provided without immediate or advance payment being requested?).

The nature of the interactions among individuals in a community (whether this is a street, neighbourhood or city) offers indications on the social capital of the community and thus on the quality of life. Social contacts, willingness to help others or to engage in volunteer activities (individually, in non-profit organizations or in social economy enterprises) are positively correlated with welfare. A study in the early 1990s, carried out worldwide, in which 35 countries were involved, showed that social trust and civic engagement are strongly correlated; the higher the degree of association of the members of a society, the greater the trust of its citizens (Apud Putnam, R.D., 1995, pp. 73).

We cannot conclude this paper without highlighting that volunteering has at least a dual role in a community: social and economic. Two examples can be enlightening in this respect: an estimation of volunteering in the United States shows that in 2003, more than 63.80 million $(28.8 \%$ ) of the Americans aged over 16 years were engaged in voluntary activities and volunteering provided economic benefits to the society - 15.0 billion formal volunteer hours, with an estimated value of 182 billion dollars (Apud Houle, B.J., Sagarin, B.J. \& Kaplan, M.F., 2005, pp. 337). By contrast, in Romania, in 2012, the Federation Volume (a federation that supports volunteering) reported 2.53 million volunteer hours (!) cumulated in 90 projects (http://www.galavoluntarilor.ro/ accessed on 03.04.2016, at 2.50 p.m.). Looking at these huge differences between the statistics of the two countries, we may ask ourselves the following question: Could it be that the participation in volunteering is one of the factors that differentiates the two countries from the economic point of view? Instead of answering the question, we prefer to outline the fact the social economy enterprises have a vital role in local communities, including an economic one, through the direct and indirect benefits gained as a result of paid work and of volunteering.

\section{References}

Ailenei, D., (coordinator) 2007. Diminishing inequalities - essential condition for economic and social cohesion, research contract no. 91-050/21.09.2007 PN II - Partnerships in priority areas.

Chelcea, S., 2001. Techniques of sociological research.

Coman, A., Pop, I., 2012. Teaching Social Entrepreneurship in Universities. The case of the Maramures County, Romania. 
Cozarescu, M., 2012. The Social Economy in Romania, between praxis and the need of conceptualizing practice. Journal of Community Positive Practices, 12(1), p.124.

Cronbach, L. J., 1951. Coefficient Alpha and The Internal Structure of Tests. Psychometrika (16), 3.

Demoustier, D. et Colletis, G.,2012. L'économie sociale et solidaire face à la crise : simple résistance on participation au changement? Revue internationale de l'économie sociale : Recma, n 325, pp. 21-35.

Dees, J.G., Elias, J., 1994. The challenges of combining social and commercial enterprise.

Field, A., 2006. Research Methods II: Reliability Analysis, pp. 1-7.

Hatos, A., 2010. Social data analysis. Laboratory guide, pp. 1-94.

Hoddinott, S. N., \& Bass, M. J. 1986. The Dillman Total Design Survey Method. Canadian Family Physician, 32, 2366-2368.

Houle, B.J., Sagarin, B.J. and Kaplan, M.F., 2005. A functional approach to volunteerism: Do volunteer motives predict task preference? Basic and applied social psychology, 27(4), pp.337-344.

Klein, J.D. and Pridemore, D.R., 1992. Effects of cooperative learning and need for affiliation on performance, time on task, and satisfaction. Educational Technology Research and Development, 40(4), pp.39-48.

Leviner, N., Crutchfield LR., Wells, D., 2006, Understanding the impact of social entrepreneurs: ashoka's answer to the challenge of measuring effectiveness.

Likert, R., 1935. A techniqe for the measurement of attitude.

Lochner, K., Kawachi, I. and Kennedy, B.P., 1999. Social capital: a guide to its measurement. Health \& place, 5(4), pp.259-270.

Mărginean, I., 2004. Romanian social model in terms of quality of life. Quality of life, 15(3-4), pp.1-6.

Myers, J., Mcdonald, M., 2014. Reciprocal Relationships: The Role of Government and the Social Economy in the Coconstruction of Social Policy in Atlantic Canada.

O'Connor, P., 2014. The New Regulatory Regime for Social Enterprises in Canada: Potential Impacts on Nonprofit Growth and Sustainability Ryerson University.

Opariuc-Dan, C., 2011. Applied statistics in social and buman sciences. Associations and statistical differences analysis.

Peng, L., Liang, C., 2016. Developing a social enterprise performance scale and examining the relationship between entrepreneurs' personality traits and their perceived enterprise performance, Journal of entrepreneurship, management and innovation.

Persais, E., 2013. Capital sociétal et gouvernance d'entreprise. Le cas d'entreprise de l'Économie Sociale et Solidaire. Management international, vol. 17, $\mathrm{n}^{\circ}$ 4, pp. 145-162.

Petrescu, C., 2013. Social Economy in the context of local development. Polirom Publisher, Iaşi.

Popa, M., 2011. Criterion validity of personality tests: limitations and statistical solutions

Popa, M. 2011. „Infidelity” of Cronbach alpha reliability coefficient. Psychology of Human Resources, Vol. 9, Nr. 1, pp. 85-99.

Popa, M., 2014 Analiza de itemi din perspectiva teoriei clasice a testului.

Popescu, D., Sanchez, G.A., Nicolae, V., \& All, 2015. Empirical research regarding the importance of volunteering for the sustainable development of social economy enterprises, Economic Computation and Economic Cybernetics Studies and Research, Issue 4/2015.

Putnam, R.D., 1993. The prosperous community. The american prospect, 4(13), pp.35-42.

Putnam, R.D., 1995. Bowling alone: America's declining social capital. Journal of democracy, 6(1), pp.65-78.

Sahakian, M.D., Dunand, C., 2014. The social and solidarity economy towards greater 'sustainability': learning across contexts and cultures, from Geneva to Manila, pp 403, Oxford University Press and Community Development Journal.

Sibony, D., 2013. Capital social, philanthropie et identite : quelles implications pour l'economie sociale?. Business administration. Conservatoire national des arts et metiers - CNAM, French.

Șandor, S.D., 2012. Methods and techniques of research in social sciences.

Ticu, C., 2008. Analysis of organizational climate, in the book „Psychology organizational and managerial. Current Tendencies” (coord Avram E. şi Cooper C. L.), Polirom Publisher, Iaşi (pp 171 - 196).

Voicu, B., 1998. Social exchange, social exchanges, Journal of Social Research, no. 2/1998, pp. 142-162.

Woolcock, M., 1998. Social capital and economic development: Toward a theoretical synthesis and policy framework. Theory and society, 27(2), pp.151-208.

Zheliazkov, G. and Stoyanov, K., 2015. The social enterprise as an alternative economic model for small and mediumsized enterprises. Examples of successful social enterprises. Trakia Journal of Sciences, 13(1), pp.274-277.

https://dexonline.ro, accessed permanently.

http://www.merriam-webster.com/dictionary/, accessed permanently. 